\title{
Quyền lực tỉnh thức và những hoạt động bác ái đóng góp cho xã hội
}

\author{
Hồ Mạnh Toàn \\ A.I. for Social Data Lab (AISDL) \\ toan@sshpa.com
}

Hà Nội, 24-01-2019

SSHPA (23-1-2019; Cập nhật bổ sung từ bài SciComm trên SSHPA [1]) Tài tử Châu Nhuận Phát sở hữu một gia tài điện ảnh khổng lồ và khối tài sản lên đến hơn 700 triệu đô la. Thế nhưng, cũng như nhân vật Lý Mộ Bạch trong tác phẩm kinh điển Ngọa hổ tàng long (2000) luôn muốn rời bỏ giang hồ, sống một cuộc đời lặng lẽ, cuộc sống giản dị của Châu Nhuận Phát ngay giữa Hồng Kông huyên náo khiến báo chí phải xôn xao. Hàng ngày, ông đều di chuyển bằng phương tiện công cộng, vì nó mang lại sự tiện nghi lớn. Thậm chí, ông còn xếp hàng mua vé để xem chính bộ phim mà mình đóng. Trong tương lai, ông dự định sẽ quyên góp toàn bộ khối tài sản của mình cho các hoạt động thiện nguyện sau khi ông qua đời [2]. Ông cho rằng: "Tiền bạc chưa bao giờ là thứ ta mãi sở hữu. Ngày mà ta chết đi cũng là lúc ta phải để nó lại cho người khác" [3].

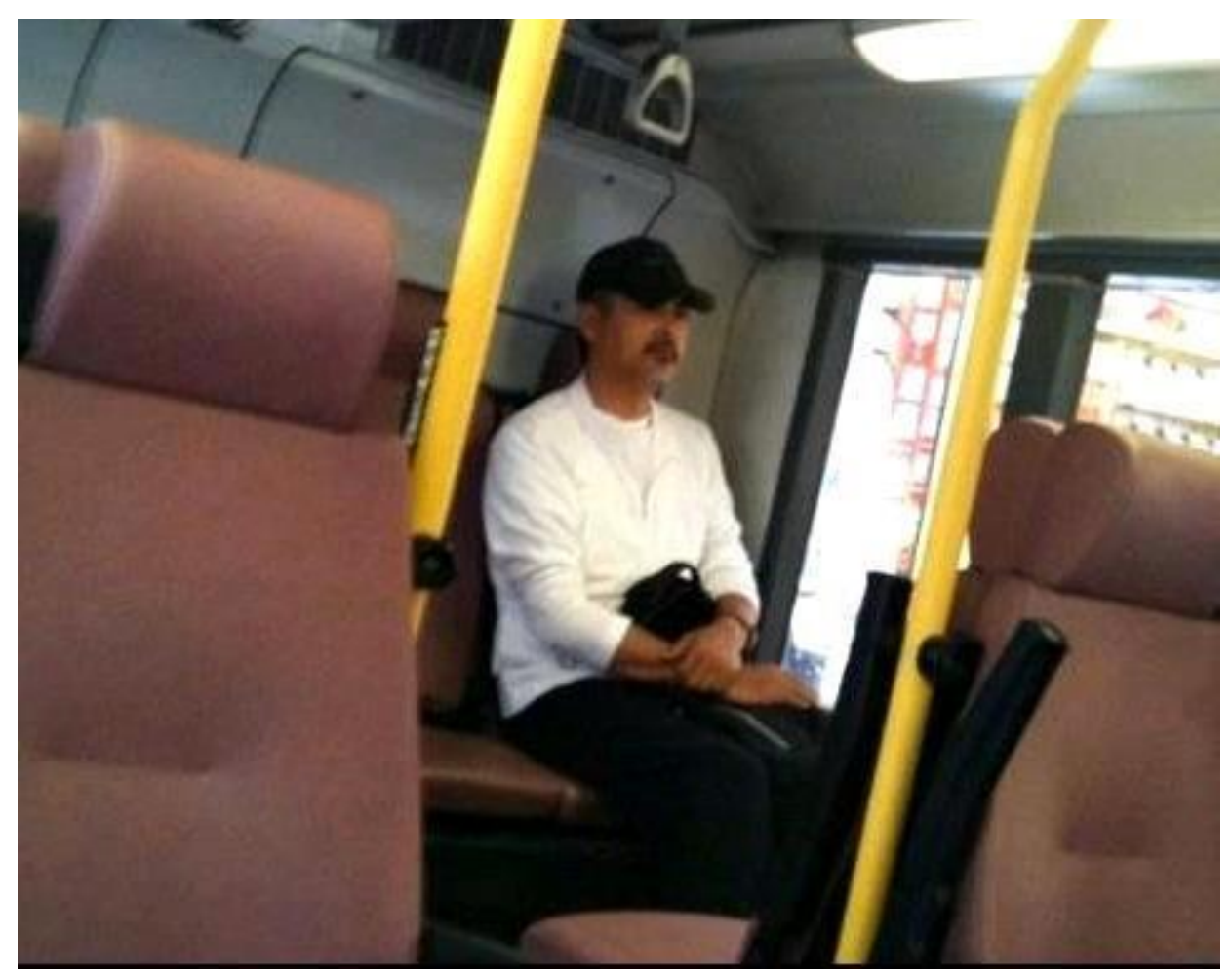

(Nguồn: Reddit) 
Cuốn Bằng chứng cuộc sống - Suy nghĩ về phát triển bền vững Việt Nam có đoạn [4]:

Sự thức tỉnh của quyền lực kinh tế trước các giá trị mỹ học và văn hóa của khoa học - công nghệ đã trở thành một mô thức vận hành của thế giới hiện đại, đặc biệt ở các xã hội có trình độ văn hóa phát triển cao. Thường những hoạt động không vì lợi ích cá nhân của những nhân vật đứng đầu các trung tâm quyền lực kinh tế và công nghệ được gán chung cho ý niệm "từ thiện". Trên thực tế, cách gọi đó có phần không phản ánh được ảnh hưởng sâu sắc và sự đóng góp lớn cho quá trình tiến hóa, hoàn thiện nhân cách và phương thức sống của con người, dẫn dắt bởi nhóm tri thức tinh hoa. Có lẽ, cách gọi khác có thể phản ánh tốt hơn bản chất là "hoạt động bác ái".

Tại Hollywood xô bồ, cố diễn viên Paul Walker từng trả hơn US\$9000 đô để mua tặng một cặp nhẫn đính hôn cho cặp đôi anh tình cờ gặp [5]. Một diễn viên nổi tiếng khác cũng luôn được nhắc đến vì sự giản dị và bác ái của mình là Keanu Reeves. Người ta dễ dàng bắt gặp anh trên tàu điện ngầm, ngồi bên lề đường ăn bánh, hút thuốc với một người vô gia cư. Những người từng có cơ hội hợp tác với Keanu chắc chắn đều cảm động vì tấm lòng của anh [6]: mua bữa ăn trưa cho mọi người, ủng hộ một thành viên gặp khó khăn trong đoàn làm phim US $\$ 20000$ đô la, hay tự đầu tư vào bộ ba The Matrix để đảm bảo mọi người trong đoàn làm phim sẽ có công ăn việc làm.

Đối với những ngôi sao nổi tiếng, họ tác động đến những người xung quanh một cách trực tiếp thông qua những hành động nhỏ nhưng ý nghĩa. Còn với những quyền lực kinh tế thực sự, họ góp phần thúc đẩy xã hội bằng những đóng góp to lớn cho sự phát triển khoa học công nghệ của nhân loại.

Elon Musk từng tuyên bố trên Twitter của mình rằng nếu muốn kiếm tiền, ông đã có thể làm một công ty Internet. Thực tế, lịch làm việc của ông khiến mọi người phải giật mình với khoảng 120 giờ làm việc mỗi tuần, nhiều thời gian ngủ trên sàn phòng làm việc [7]. Ngay cả trong kì nghỉ, ông cũng luôn thảo luận về các dự án lên sao Hỏa, hay ảnh hưởng của biến đổi khí hậu. Làm thế nào để có thể giúp ích cho nhân loại và con người? Đó là câu hỏi mà ông đang cố trả lời với hàng loạt các dự án của Tesla, Hyperloop hay SpaceX.

Ngược về lịch sử vào năm 1911 tại Brussels (Bỉ), Hội nghị Solvay (Conseil de Physique Solvay) [8] lần đầu tiên được tổ chức. Kể từ đó, cứ 3 năm một lần, những nhà khoa học tiêu biểu đương thời sẽ tụ họp tại hội nghị. Nổi tiếng nhất là vào năm 1927, các vĩ nhân như Albert Einstein, Max Planck, Marie Curie, Erwin Schrödinger ... tụ họp tại Hội nghị Solvay lần thứ 5 . Hội nghị luôn nhận được sự cảm kích lớn từ các nhà vật lý và hóa học vì nó đã góp phần thúc đẩy các hoạt động khoa học của nhân loại [4]. Bên cạnh đó, di sản của Ernest Solvay (1833-1922) còn là các hoạt động khoa học rộng khắp như các Viện Vật lý, Viện Xã hội, hay trường Thương mại Solvay (thuộc Université libre de Bruxelles). Bằng tiềm lực kinh tế mạnh mẽ do chính ông tạo dựng - Tập đoàn Solvay (https://www.solvay.com/en) - Ernest Solvay đã thúc đẩy không chỉ nước Bỉ mà cả nền khoa học châu Âu vượt lên, bằng cách tập hợp những bộ não vĩ đại nhất, để bàn luận những vấn đề quan trọng nhất của thời đại. 


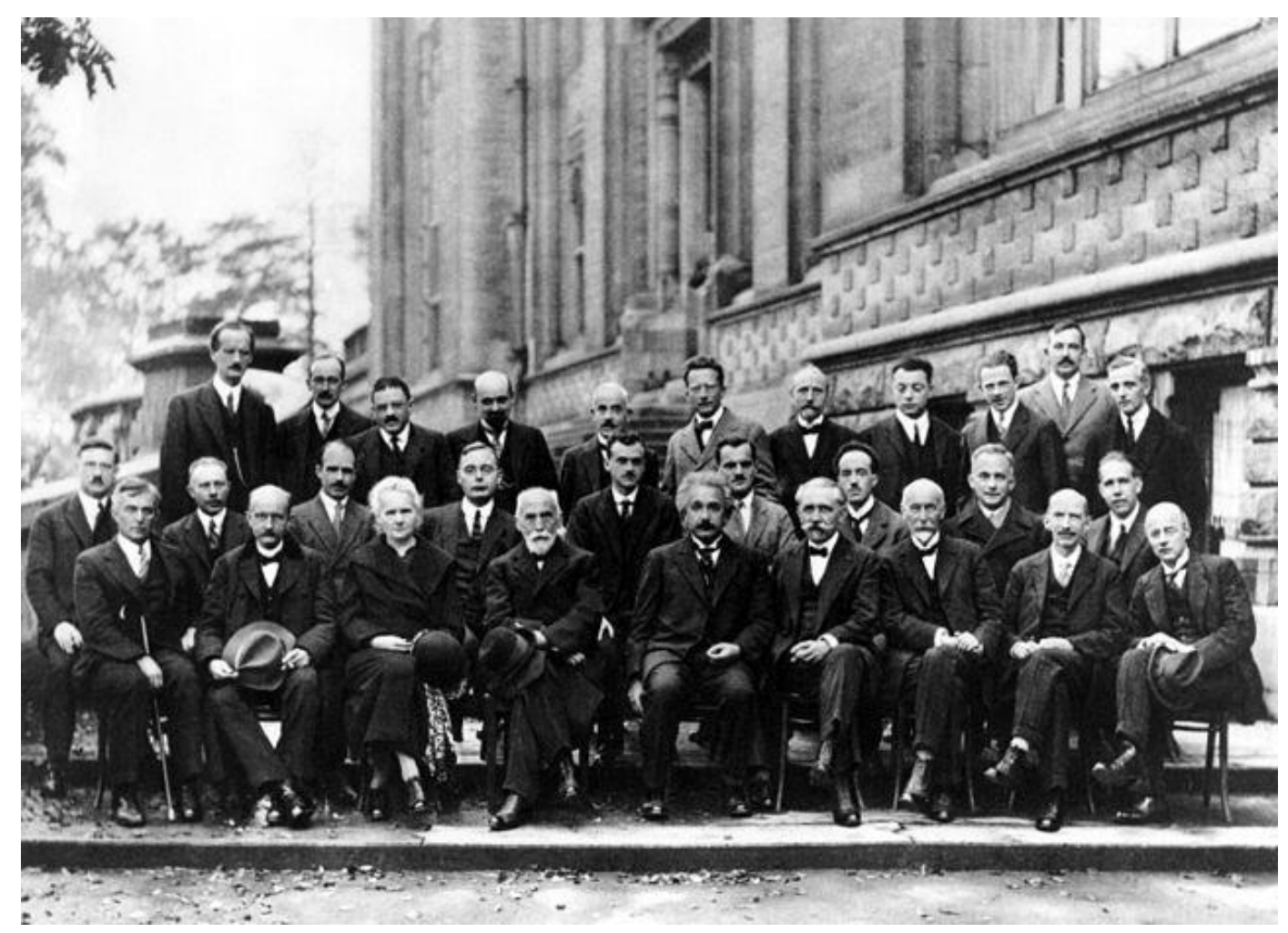

(Nguồn: Wikipedia)

Hiện nay, bên cạnh những người đang trực tiếp sáng tạo, truyền cảm hứng như Elon Musk, ông trùm công nghệ Bill Gates và quỹ Bill and Melinda Gates Foundation cũng đã và đang mang đến những đóng góp to lớn cho giới khoa học với các khoản tài trợ khổng lồ mỗi năm, hay tiếng nói quan trọng trong ủng hộ các phong trào khoa học như Open-Access [9].

Đó là "quyền lực tỉnh thức" của những người có quyền lực kinh tế - chính trị nghệ thuật. Họ có thể không trực tiếp đóng góp công sức, lao động, ý tưởng nhưng họ kiến tạo một nền văn hóa ủng hộ khoa học công nghệ bằng tiềm lực, vị thế của mình trong xã hội thông qua những "hoạt động bác ái" [4].

Hiện nay, các quan niệm truyền thống như Nho giáo vẫn ăn sâu trong xã hội Việt Nam, cả trong các lĩnh vực cần sự sáng tạo, đổi mới không ngừng như khoa học, nghệ thuật, hay khởi nghiệp $[10,11,12]$. Vì vậy, sự phát triển khoa học tại Việt Nam nói chung, và xã hội Việt Nam nói riêng, chắc chắn sẽ cần tới những con người bác ái, hay những người nổi tiếng giản dị, đam mê khoa học $[13,14]$ để tác động đến xã hội, chạm tới công chúng. Họ sẽ góp phần đẩy mạnh những cuộc đối thoại tri thức, giúp người dân hiểu hơn về giá trị của khoa học [15], góp phần kiến thiết những giá trị quan trọng cho sự phát triển bền vững lâu dài của xã hội. 


\section{References:}

[1] SciComm SSHPA. (2019). Quyền lực tỉnh thức và những hoạt động bác ái đóng góp cho xã hội. Địa chỉ: https://sc.sshpa.com/post/4378 [Jan 24, 2019].

[2] Telegraph Reporters. (2018). Hong Kong actor Chow Yun-Fat to give $£ 542$ million fortune away. The Telegraph. Retrieved from https://www.telegraph.co.uk/films/2018/10/16/hong-kong-actor-chowyun-fat-give-542-million-fortune-away/ [Jan 24, 2019].

[3] MacLellan, L. (2018). The surprisingly modest lifestyle of one of the world's wealthiest actors. Quartz. Retrieved from https://qz.com/1506767/thehumble-lifestyle-of-movie-star-chow-fat-yun/amp/ [Jan 24, 2019].

[4] Bạch, N. C., \& Vương, Q. H. (2015). Bằng chứng cuộc sống: Suy ngẫm về phát triển bền vũng Việt Nam. Hà Nội: Nhà xuất bản Chính trị Quốc gia - Sự thật.

[5] Dockterman, E. (2013). Paul Walker bought $\$ 9,000$ engagement ring for military couple who couldn't afford it. Time. Retrieved from http://entertainment.time.com/2013/12/04/paul-walker-bought-9000engagement-ring-for-military-couple-who-couldnt-afford-it/ [Jan 24, 2019].

[6] Wright, M. (n.d.). 10 times Keanu Reeves proved to be a real-life hero. The Power of Silence. Retrieved from https://thepowerofsilence.co/10-times-keanureeves-proved-real-life-hero/ [Jan 24, 2019].

[7] Gelles, D. (2018). In Elon Musk's world, brakes are for cars, not C.E.O.s. The New York Times. Retrieved from https://www.nytimes.com/2018/08/28/business/elon-musk-tesla.html [Jan 24, 2019].

[8] Wikipedia contributors. (2019, January 12). Solvay Conference. In Wikipedia, The Free Encyclopedia. Retrieved from https://en.wikipedia.org/w/index.php?title=Solvay Conference\&oldid= 878023935 [Jan 24, 2019].

[9] SciComm SSHPA. (2018). Hai quỹ tài trợ khoa học lớn tuyên bố ủng hộ 'Kế hoạch S'. Địa chỉ: https://sc.sshpa.com/post/4335 [Jan 24, 2019].

[10] Vuong Q. H., Tran T. D. (2009). The cultural dimensions of the Vietnamese private entrepreneurship. IUP Journal of Entrepreneurship Development, VI(3-4): 54-78.

[11] Vuong, Q.H., Ho, M.T., Vuong, T.T., Tran, K., \& Ho, M. (2018b). “Paintings can be forged, but not feeling": Vietnamese art-Market, fraud, and value. Arts, 7(4), 62, doi: $10.3390 /$ arts7040062.

[12] Vuong, Q. H., La, V. P., Vuong, T. T., Nguyen, V. H., Ho, M. T., Nguyen, T. H. K., Bui, Q. K., Ho, M. T. (2018). Cultural additivity: Behavioural insights from the 
interaction of Confucianism, Buddhism, and Taoism in folktales. Palgrave Communications, 4, DOI: 10.1057/s41599-018-0189-2.

[13] SciComm SSHPA. (2018). Diễn viên đoạt giải Oscar-Natalie Portman-công bố khoa học. Địa chỉ: https://sc.sshpa.com/post/2134 [Jan 24, 2019].

[14] SciComm SSHPA. (2018). Những nghệ sĩ khoa học. Địa chỉ: https://sc.sshpa.com/post/4238 [Jan 24, 2019].

[15] Vuong, Q. H. (2018). The (ir)rational consideration of the cost of science in transition economies. Nature Human Behaviour, 2(1), 5, DOI:

10.1038/s41562-017-0281-4. 